\title{
Effect of Ether Electrolyte on the Electrochemical Performance of $\mathrm{Cu}_{2} \mathrm{~S}$
}

\author{
Yingjie Zhang ${ }^{1}$, Yongtai $\mathrm{Li}^{2}$, Qiao Zhang ${ }^{3}$, Chuan $\mathrm{Shi}^{4}$, Xue Li ${ }^{1, *}$, Yiyong Zhang, ${ }^{1, *}$ \\ ${ }^{1}$ Faculty of Metallurgical and Energy Engineering, Kunming University of Science and Technology, \\ Kunming 650093, China. \\ ${ }^{2}$ Faculty of Materials Science and Engineering, Kunming University of Science and Technology, \\ Kunming 650093, China. \\ ${ }^{3}$ Faculty of Science, Kunming University of Science and Technology, Kunming 650093, China. \\ ${ }^{4}$ College of Physics, Qingdao University, Qingdao, 266071, China.. \\ *E-mail: 438616074@qq.com
}

doi: $10.20964 / 2020.04 .78$

Received: 4 January 2020 / Accepted: 15 February 2020 / Published: 10 March 2020

\begin{abstract}
With the widespread popularization of rechargeable portable devices, lithium-ion batteries have been researched in depth and have brought huge economic benefits. To improve the energy density and safety of lithium-ion batteries, research on new materials is urgent. $\mathrm{Cu}_{2} \mathrm{~S}$ has attracted the attention of researchers for its excellent physicochemical properties. It not only has an excellent reversibility of electrochemical lithium storage with high energy density but also has a low manufacturing cost. The electrolyte is responsible for transporting electrons and ions in the lithium battery. It is one of the important modules of the battery and has an important impact on the electrochemical performance of the battery. At present, there is very little research on the suitable electrolytes for $\mathrm{Cu}_{2} \mathrm{~S}$. The effects of different types of ether electrolytes on the electrochemical performance of $\mathrm{Cu}_{2} \mathrm{~S}$ are studied in this paper. In addition, an activation process of the $\mathrm{Cu}_{2} \mathrm{~S}$ electrode material during the initial cycles is also studied.
\end{abstract}

Keywords: Cuprous sulfide, Electrolyte, Activation process

\section{$\underline{\text { FULL TEXT }}$}

(C) 2020 The Authors. Published by ESG (www.electrochemsci.org). This article is an open access article distributed under the terms and conditions of the Creative Commons Attribution license (http://creativecommons.org/licenses/by/4.0/). 